\title{
Deforestation, host community structure, and amphibian disease risk
}

8

9

24 * Corresponding author. Tel.: +55 1999998 2212. E-mail address: cgb58@cornell.edu.
C. Guilherme Becker ${ }^{\mathrm{ab}}$, David Rodriguez ${ }^{\mathrm{c}}$, Ana V. Longo ${ }^{\mathrm{a}}$, L. Felipe Toledo ${ }^{\mathrm{d}}$, Carolina Lambertini ${ }^{\mathrm{d}}$, Domingos S. Leite ${ }^{\mathrm{d}}$, Célio F. B. Haddad ${ }^{b}$, and Kelly R. Zamudio ${ }^{a}$

\section{Author affiliations:}

a-Department of Ecology and Evolutionary Biology, Cornell University, Ithaca, NY 14853, U.S.

b-Departamento de Zoologia, Universidade Estadual Paulista, Rio Claro, SP 13506, Brazil.

c-Department of Biology, Texas State University, San Marcos, TX 78666, U.S.

d-Departamento de Biologia Animal, Universidade Estadual de Campinas, Campinas, SP 13083, Brazil. 


\section{Abstract}

Habitat disturbances and the emergence of the chytrid fungus Batrachochytrium dendrobatidis $(B d)$ are linked to accelerated amphibian declines. Deforestation can directly alter amphibian community structure through abiotic and biotic mechanisms including shifts in local microclimates and species interactions. Changes in amphibian community attributes, in turn, potentially impact $B d$ transmission dynamics, and thus also have an indirect role in biodiversity persistence. Here, we tested whether deforestation influences $B d$ infections through shifts in amphibian community structure, including species richness, community composition, total host density, and host biomass. We surveyed 22 temperate and tropical amphibian communities across gradients of deforestation in the U.S. and Brazil, and we experimentally exposed a representative subsample of each amphibian community to standardized $B d$ zoospore loads in mesocosms under controlled microclimate. We found that denser temperate amphibian communities commonly found at pristine sites showed higher $B d$ loads when microclimates were held constant. In contrast, tropical amphibian communities found at pristine forest sites carried lower $B d$ infection loads in the absence of variable microclimates, likely due to their host species composition. Previous host exposure to the pathogen in tropical communities also played an important role in determining infection loads; we identified a negative association between $B d$ infection loads observed in the wild and in the laboratory. Our results highlight that deforestation can have cascading biotic effects on disease risk, and that quantifying the net contribution of host community attributes to $B d$ infections will help us identify specific drivers of disease and inform conservation strategies. Keywords: Species diversity, wildlife diseases, amphibian declines, acquired resistance, densitydependent transmission 
Zusammenfassung

Störungen des Lebensraumes und das Auftreten des Chytridpilzes, Batrachochytrium dendrobatidis $(\mathrm{Bd})$, stehen mit dem beschleunigten Rückgang der Amphibien in Verbindung. Entwaldung kann die Struktur einer Amphibiengemeinschaft direkt durch abiotische (lokales Mikroklima) oder biotische (interspezifische Interaktionen) Mechanismen verändern. Diese Veränderungen der Amphibiengemeinschaft könnten ihrerseits die Bd-Übertragungsdynamik beeinflussen und so eine indirekte Rolle für den Erhalt der Biodiversität spielen. Wir untersuchten, ob Entwaldung über Änderungen der Struktur von Amphibiengemeinschaften die Bd-Infektionen beeinflusste. Wir erfassten dazu Artenreichtum, Artenzusammensetzung, gesamte Wirtsdichte und Wirtsbiomasse von 22 gemäßigten (USA) und tropischen (Brasilien) Amphibiengemeinschaften, die Gradienten von unterschiedlicher Bewaldung repräsentierten. In Mesokosmen mit kontrolliertem Mikroklima setzten wir repräsentative Proben aller Amphibiengemeinschaften standardisierten Bd-ZoosporenBelastungen aus. Wir fanden, dass individuenreiche gemäßigte Gemeinschaften, die gewöhnlich an unberührten Standorten gefunden wurden, höheren Bd-Befall zeigten, wenn das Mikroklima konstant gehalten wurde. Dagegen waren tropische Gemeinschaften aus unberührten Habitaten bei konstantem Mikroklima geringer infiziert, vermutlich bedingt durch ihre Artenzusammensetzung. Frühere Exposition der Wirte in tropischen Gemeinschaften spielte eine wichtige Rolle: wir fanden eine negative Beziehung zwischen Bd-Infektion im Freiland und im Labor. Unsere Ergebnisse zeigen, dass Entwaldung kaskadierende biotische Effekte auf das Befallsrisiko haben kann und dass die Quantifizierung des Netto-Beitrags der Parameter der Wirtsgemeinschaften zur Bd-Infektion uns helfen wird, spezifische 


\section{Introduction}

Amphibian biodiversity is declining worldwide at unprecedented rates (IUCN et al. 2014). Two important factors implicated in population declines and extinctions are habitat loss (Cushman 2006, Becker et al. 2007) and chytridiomycosis, a disease cause by the chytrid fungus Batrachochytrium (Skerratt et al. 2007, Martel et al. 2014). Loss of natural vegetation changes amphibian community structure by increasing population isolation (Arens et al. 2007), inbreeding (Andersen et al. 2004), edge effects, and discontinuity between terrestrial and aquatic habitats (Rittenhouse \& Semlitsch 2006, Becker et al. 2010). Disturbances to natural habitats also shift both macro (Costa \& Foley 2000) and microclimates (Kapos 1989). Therefore, habitat loss can have potentially large effects on amphibian susceptibility to disease by altering host community attributes and optimum microclimates for both amphibian hosts and pathogens (Raffel et al. 2010, Becker et al. 2012). The frog killing fungus Batrachochytrium dendrobatidis $(B d)$ is a waterborne epidermal pathogen with a broad host range among anurans (Fisher et al. 2009). Because many amphibian species share aquatic breeding sites (e.g., ponds, streams), inter-host transmission is common (Searle et al. 2011). Free-swimming zoospores shed by infected individuals colonize the skin of other hosts and proliferate, causing chytridiomycosis (Longcore et al. 1999). Shifts in amphibian community attributes likely influence $B d$ transmission dynamics (Searle et al. 2011, Venesky et al. 2014a, Becker et al. 2014), because host species vary in their susceptibility to infection (Gervasi et al. 2013) and possibly shed zoospores into aquatic habitats at different rates. Likewise, densitydependent transmission (Searle et al. 2011, Venesky et al. 2014a) will also cause potential changes in host-pathogen dynamics as populations and communities shrink or expand in modified habitats. Therefore, we predict that following anthropogenic habitat alteration, shifts in host community composition and density will have potentially large impacts on pathogen burden and disease risk. 
Host community attributes such as species richness, species composition, total host density,

107 and biomass can be precisely quantified across amphibian communities in the wild. However, their

108 effects on host-pathogen dynamics are often confounded by the influence of abiotic factors that

109 independently regulate pathogen abundance or host exposure. For instance, the influence of

110 microclimate on likelihood of amphibian infection by $B d$ is unequivocal. Mounting evidence points

111 to direct effects of temperature and humidity on $B d$ growth and persistence both in the laboratory

112 and in the wild (Raffel et al. 2006, Raffel et al. 2010, Becker \& Zamudio 2011, Becker et al. 2012,

113 Raffel et al. 2015). Because deforestation drastically changes local microclimates (Kapos 1989),

114 along with the aforementioned host community attributes (Chapin et al. 2000), integrative field and

115 laboratory studies of host- $B d$ dynamics are necessary if we are to understand the contribution of

116 biotic variables to disease dynamics.

117 Here, we tested whether anthropogenic changes to natural vegetation influence $B d$ infection

118 dynamics through shifts in amphibian community attributes. Specifically, we used a combination of

119 field surveys and mesocosm experiments to address hypotheses about the role of habitat change in

120 mediating disease risk through shifts in host species richness, community composition, total host

121 density and biomass. We surveyed and $B d$-screened 22 natural amphibian communities in

122 temperate and tropical landscapes and quantified the effect of deforestation on host species

123 composition and relative abundance across sampling sites. We then experimentally exposed a

124 representative sample of each host community to standardized $B d$ zoospore loads in mesocosms to

125 test the effect of host community attributes on $B d$ infection dynamics under controlled

126 microclimates. Combined, our field surveys and mesocosm experiments quantify the net

127 contribution of host community structure to host-pathogen dynamics. Experimentally testing how

128 anthropogenic habitat change influences $B d$ infection intensity in ecologically realistic communities 
129 is critical for the development of appropriate conservation efforts in the wake of accelerated habitat 130 destruction.

Materials \& methods

133 Study sites and GIS analyses

134 We surveyed amphibians from ten permanent ponds (mean circumference $=114.75 \mathrm{~m} \pm 49.47 \mathrm{SD}$ )

135 in Eastern Forest-Boreal Transition (Adirondack Park) of the northeastern U.S. (43 $15^{\prime}$ N; $74^{\circ} 35^{\prime}$

$136 \mathrm{~W}$ ) and 12 permanent ponds (mean circumference $=130.90 \mathrm{~m} \pm 53.49 \mathrm{SD}$ ) in the Serra do Mar

137 Coastal Forest in southeastern Brazil (23 $\left.13^{\prime} \mathrm{S} ; 45^{\circ} 20^{\prime} \mathrm{W}\right)$. We quantified undisturbed forest cover

138 for each sampling site based on high-resolution orthophotos from 2008-2009 (15 and $30 \mathrm{~cm}$

139 resolution; [USGS 2010]) for the U.S. and high-resolution satellite images from 2010 (SPOT, 2-m

140 resolution) for Brazil. For both temperate and tropical landscapes, study sites were chosen along a

141 vegetation gradient from disturbed/open to pristine/closed-canopy vegetation cover. At each

142 sampling site, we quantified the percentage of undisturbed forest cover in a radius of $30 \mathrm{~m}$ from the

143 edge of the pond using ArcGIS v.10 (ESRI 2013). In our study, we classified primary or secondary

144 mature forests as undisturbed forest cover. We classified urban, pasture, agriculture, silviculture,

145 recreational land (e.g., golf-courses, soccer fields), and natural vegetation in early successional

146 stages as disturbed land-cover types. We recorded surface water temperatures for each of our

147 sampling ponds using waterproof pendant data loggers (Hobo UA-002-64; $0.1 \mathrm{u}^{\circ} \mathrm{C}$ resolution). We

148 placed three data loggers (spaced equidistantly) in each pond at $10 \mathrm{~cm}$ depth and used $30 \mathrm{~min}$

149 interval records taken simultaneously at all ponds to calculate daily average temperatures at each

150 site. To avoid confounding effects of elevation and macroclimate across our sampling ponds, we

151 explicitly chose landscapes with low climatic and topographic variability (Becker \& Zamudio 2011,

152 Becker et al. 2012). 
156 We conducted visual encounter surveys in ponds in the Adirondack Park during the boreal summer

157 (June), and in ponds in Brazil during the austral summer (November) of 2012. At each sampling

158 pond, we surveyed amphibian communities over three consecutive nights to obtain comparable data

159 on amphibian species composition and relative abundance among sites in our disturbance gradients.

160 We performed visual surveys within a $3 \mathrm{~m}$ buffer from the water line. Surveys at all ponds in each

161 landscape occurred within a window of seven or six days. In each landscape, we standardized

162 survey effort (person.hours) across our focal ponds (150 person.hours and 280 person.hours in

163 temperate and tropical landscapes, respectively). Using these pond survey data, we estimated

164 amphibian species composition and relative abundance across ponds. After this initial survey we

165 collected (and swabbed) a representative subsample of individual amphibians from each pond

166 mimicking host species richness, density, and total biomass from natural communities for posterior

167 mesocosm experiments (see more details below).

168 This short time period for surveys reduces the potential bias of variable meteorological or

169 seasonal conditions that occurs over longer sampling periods. The potential disadvantage of our

170 survey is that it did not capture early-breeding species that may contribute to transmission dynamics

171 from earlier reproductive bouts. Likewise, although tadpoles can serve as pathogen reservoirs, and

172 most certainly play an important role in $B d$ dynamics (Briggs et al. 2010), our study focused on

173 post-metamorphic amphibians. Although these life stages and early breeders were not quantified,

174 our survey data capture the main adult species contributing to transmission and persistence of $B d$ at 175 that point in time. 
178 We brought to the laboratory representative subsamples of amphibian communities for a total of 10

179 temperate and 12 tropical mesocosm communities. We used our initial survey data on host relative

180 abundance (by species and among sampling ponds) to create mesocosm assemblages that mimicked

181 host community attributes (density and species relative abundance) observed in the field. For our

182 temperate amphibian assemblages, we established a limit of 20 individuals maximum per

183 experimental tank, resulting in assemblages that ranged from 3-20 individuals based on capture

184 rates observed among natural ponds. Our field surveys in Brazil showed a much greater variation in 185 amphibian numbers among sampling ponds. For our tropical amphibian assemblages, we

186 established a maximum of 29 individuals per experimental tank, resulting in assemblages that 187 ranged from 2-29 individuals based on capture rates observed among natural ponds (see Appendix 188 A). Thus, we included a total of five temperate amphibian species and 14 tropical amphibian 189 species in our experiments; species richness in mesocosms varied from one to three species in 190 temperate assemblages and two to five species in tropical assemblages.

191 Each experimental unit consisted of a large water tank (120 cm diameter x $100 \mathrm{~cm}$ height $)$

192 with terrestrial habitat covering one half of the container (i.e., autoclaved moist Sphagnum moss)

193 and aquatic habitat on the other half. We covered each experimental unit with plastic mesh to

194 prevent escapes. We maintained all tanks indoors at a constant room temperature of $20{ }^{\circ} \mathrm{C}$ to control 195 for microclimatic variation.

Host community attributes in mesocosms

198 We define host species richness as the number of amphibian species in each experimental unit. As $199 B d$ potentially infects all host species used in this study (Becker \& Zamudio 2011, Becker et al. 200 2012), we quantified total host density as the total number of individual amphibians within each 
201 experimental unit. Similarly, we measured biomass as the sum of body mass across all individual

202 hosts within each experimental unit. In addition to these community attributes, we measured two

203 variables (community similarity and host aquatic index) that quantify sampled communities in

204 terms of species composition and life-histories, both factors potentially influencing the likelihood of

$205 B d$ infection in the community. We consolidated data on species composition and relative

206 abundance across sampling ponds employing Non-Metric Multidimensional Scaling (NMDS) using

207 Bray-Curtis dissimilarity matrices. We performed NMDS analyses independently for temperate and

208 tropical assemblages, using NMDS axes 1 and 2 as a metric of community similarity. Ecologically

209 similar communities tend to have similar NMDS values, and therefore, NMDS axes are to some

210 extent a proxy for host identity and relative abundance among communities. The second variable is

211 an index representing how much each species uses aquatic habitats during their lifetime (aquatic

212 index; AI; modified from Lips et al. 2003), thus this index quantifies the degree of $B d$ exposure and

213 transmission (Lips et al. 2003). Arboreal species (i.e., Hylidae) that spend less time in water were

214 coded $\mathrm{AI}=1$ and species occupying aquatic vegetation and moist terrestrial microhabitats around

215 ponds (i.e., Leptodactylidae, Ranidae, Bufonidae, Cycloramphidae) were coded as AI=2. We then

216 averaged AI across all individuals in each experimental unit, reaching a weighted average AI for

217 each community (see Appendix A).

218

219 Experimental infections

220 Prior to the experimental infections with temperate amphibians, we cleared frogs of $B d$ in the

221 laboratory by keeping all animals housed at a temperature of $31^{\circ} \mathrm{C}$ for 12 consecutive days and

222 changing the water every three days (Woodhams et al. 2003). Prior to the experimental infections in

223 Brazil, we administrated a 7-day disinfection treatment using Itraconazole at $0.01 \%$ solution

224 (Pessier \& Mendelson 2010). In both cases, we verified clearance of pathogens from all frogs using 
qPCR and allowed a four-day post-treatment recovery time prior to the beginning of the experimental infection.

For experimental infections, we inoculated temperate and tropical amphibians using two locally isolated $B d$ strains. We cultured global panzootic $B d$ strains JEL404-Maine-U.S. (used for temperate amphibians; Gahl et al. 2012) and CLFT023-MinasGerais-Brazil (used for tropical amphibians; Schloegel et al. 2012) at $19{ }^{\circ} \mathrm{C}$ for $7 \mathrm{~d}$. We harvested $B d$ by flooding plates with

231 distilled water and waiting $\sim 3 \mathrm{~h}$ for zoospore release. We then pooled water with zoospores from 232 multiple plates, quantified zoospores with a hemocytometer, and added $\sim 10^{7}$ zoospores in $6 \mathrm{~L}$ of 233 dechlorinated water to each experimental unit. This protocol guaranteed comparable infection 234 regimes across replicates with $B d$ strains naturally experienced by the hosts in the wild. We added $235 B d$-negative amphibians to the terrestrial habitat of each experimental unit and kept temperatures at $23620^{\circ} \mathrm{C}$ on a $12 \mathrm{~h}$ day-night light cycle. We monitored amphibians daily and fed them pinhead 237 crickets and wingless flies ad libitum.

238 We swabbed all individuals prior to the experimental infection and upon termination of the 239 experiment on the 18th day post-infection. This period encompasses approximately five replication 240 cycles of the pathogen (Longcore et al. 1999) and is sufficient for $B d$ to reach high infections in 241 susceptible captive amphibians (Savage \& Zamudio 2011). In case of disease, we swabbed dead or 242 dying animals and removed them from the experimental units. We tested swabs for $B d$ using 243 Taqman qPCR (Boyle et al. 2004) with $B d$ strain-specific standards of 0.1, 1, 10, 100, and 1000 244 zoospore genomic equivalents (GE) to determine the infection intensity of $B d$ in each sample. At 245 the end of the experiment, we euthanized all animals using Benzocaine 4\% (Cornell IACUC \#2010246 0069). 
Studies addressing disease dynamics in wild host communities must take into account the tradeoff

250 between biological reality and statistical power. In previous work, we used a factorial experimental

251 design to investigate the effects of host diversity on disease without taking the direct effect of

252 deforestation into account (Becker et al. 2014). Our goal here was to mimic the impact of

253 deforestation on the structure of natural communities and quantify the consequences for host-

254 pathogen interactions. Due to limitations in the number of frogs per pond that could be captured and

255 brought to the laboratory, it was not feasible to have statistical replication within ponds in our

256 mesocosm tanks. Therefore, we employed a regression-based approach that allowed us to estimate

257 the responses of unique host assemblages to $B d$. We employed a stepwise GLM procedure, using

258 host community attributes as biological explanatory variables, to find the combinations of variables

259 that best explained $B d$ infection intensity ( $\log _{10}$ transformed) at the end of the experiment. Because

260 prior infection by $B d$ may influence susceptibility of hosts to reinfection (Raffel et al. 2010), we

261 included $B d$ infection intensity at the moment of capture in the wild as a control variable for

262 previous exposure and potential acquired resistance. We used daily average pond water

263 temperatures to account for the impact of temperature shifts and host thermal acclimation in our

264 experimental infections (Raffel et al. 2013, Raffel et al. 2015). Specifically, we calculated the

265 deviation of field temperatures at each pond from the constant temperature in mesocosms $\left(20^{\circ} \mathrm{C}\right)$,

266 as a metric of temperature shift in the analyses. We placed temperature data loggers in 12 ponds in

267 Brazil, but lost devices in four ponds due to unforeseen circumstances. Finally, we included data on 268 pond circumference in the analyses.

269 Our stepwise selection of variables was based on Bayesian Information Criterion (BIC),

270 using minimum BIC values as a cutoff for the inclusion of additional parameters (i.e., forward

271 method), thus avoiding over-fitted complex models. We did not analyze prevalence data because $>$

$27296 \%$ of the hosts became infected with $B d$ during the experiments and because infection intensity, 
measured as mean pathogen load in the community, is a better indicator of infection dynamics in mixed populations. Mortality was negligible across tropical amphibian communities (i.e., only a single frog died), and thus we only analyzed mortality for temperate amphibian communities. We used the same stepwise approach to find the combination of biotic and abiotic variables that best explain community-level $B d$ infection intensity observed in the wild ( $\log _{10}$ transformed). Finally, we quantified the effect of percent undisturbed forest surrounding sampling ponds on host community attributes using a regression-based analyses [General Linear Models with standard least squares (GLMs)], and we used Pearson correlations to cross pond circumference with percent undisturbed forest. We performed all analyses using JMP v. 10.0 (SAS 2010) and R (R Core Team 2014, Oksanen et al. 2014).

\section{Results}

In temperate amphibian communities we found marginally higher host capture rates in ponds surrounded by undisturbed forest habitats than in ponds in disturbed habitats $\left(F_{[1,8]}=4.645, \beta=\right.$ 0.087, $P=0.064$; Fig. 1A), but the amount of natural vegetation around sampling ponds did not predict host species richness, NMDS, average AI, and biomass. Temperate host communities were dominated by L. clamitans across the gradient of habitat alteration. Higher host density (i.e., capture rates as a proxy) found in ponds surrounded by undisturbed forest habitats predicted higher average $B d$ infection intensity in mesocosm amphibian assemblages $\left(F_{[1,8]}=6.410, \beta=0.067, P=0.035\right.$;

Fig. 1B). However, assemblages with high host densities did not show higher mortality rates during the course of the experiment $\left(F_{[1,8]}=2.005, P=0.194\right)$. Looking simultaneously at all explanatory biological variables controlling $B d$ infection intensity in our mesocosm, our stepwise selection of variables included total host density as the single positive predictor of $B d$. These findings were not associated with host acquired resistance, as mean $B d$ infection loads observed in the laboratory were 
unrelated to loads observed in the wild prior to the experimental infection $\left(F_{[1,8]}=0.069, P=\right.$ 0.798).

In our diverse tropical communities from Brazil, we found the same pattern of higher host capture rates in ponds surrounded by natural vegetation $\left(F_{[1,10]}=7.208, \beta=0.181, P=0.023\right)$. In these communities, we also found a significant positive effect of natural vegetation on host species richness $\left(F_{[1,10]}=5.469, \beta=0.024, P=0.041\right)$. None of the explanatory host community attributes we measured significantly predicted $B d$ loads in our mesocosm experimental infection when regressed independently. Contrary to the pattern we observed in temperate amphibians, we found that higher $B d$ exposure in natural tropical communities significantly predicted lower $B d$ loads in mesocosms $\left(F_{[1,10]}=9.476, \beta=-0.556, P=0.011\right.$; Fig. 2$)$. In addition to this strong effect of previous exposure, our stepwise selection of variables identified other important factors potentially explaining $B d$ infection intensity: NMDS, average AI, and host capture rate (Table 1). Specifically, several assemblages of species typically found in disturbed habitats showed higher $B d$ infection loads following experimental infection in the laboratory when the effect of previous exposure was controlled for. Surprisingly, mesocosms dominated by hylid species $(A I=1)$ showed higher infection loads than mesocosms dominated by riparian/terrestrial species $(A I=2)$ (Table 1).

Thermal acclimation was not a significant factor in our experiment, as $B d$ infection loads in the laboratory were unrelated to temperature shifts for both temperate $\left(F_{[1,8]}=0.321, P=0.586\right)$ and tropical amphibian assemblages $\left(F_{[1,6]}=0.013, P=0.912\right)$. Furthermore, vegetation cover and host community attributes were not significant predictors of community-level $B d$ loads observed in the wild for both temperate and tropical amphibian assemblages. Finally, pond circumference was not correlated with undisturbed forest cover (temperate: $r=0.164, \mathrm{~N}=10, P=0.719$; tropical: $r=$ $0.155, \mathrm{~N}=12, P=0.669)$ and was not a significant predictor of host density (temperate: $F_{[1,8]}=$ 2.638, $P=0.143$; tropical $F_{[1,10]}=1.317, P=0.277$ ) and species richness (temperate: $F_{[1,8]}=0.178$, 
$P=0.685 ;$ tropical $\left.F_{[1,10]}=0.708, P=0.419\right)$.

\section{Discussion}

324 The mechanisms controlling disease dynamics in wildlife can be affected by a myriad of biotic and

325 abiotic forces, which are often difficult to disentangle (Ostfeld \& Keesing 2012). Deforestation

326 raises local temperatures (Kapos 1989), which can suppress $B d$ growth and persistence in disturbed

327 habitats (Raffel et al. 2010, Becker et al. 2012). However, the impact of microclimate on $B d$

328 infection loads is expected to vary across space and time (Kriger et al. 2007, Lenker et al. 2014),

329 and thus may interact with biotic forces synergistically or antagonistically. Despite the well-known

330 influence of deforestation on $B d$ spatial epidemiology at the population level (Becker \& Zamudio

331 2011, Becker et al. 2012), we did not detect land cover effects on community-level $B d$ infections in

332 field-collected data. This is perhaps not surprising given the number of variables affecting

333 community-level disease dynamics in the wild. When controlling for the influence of microclimate,

334 we detected significant effects of host community attributes on $B d$ infection dynamics, even after

335 accounting for the effects of temperature shifts and previous host exposure.

336 Our mesocosm experiments confirmed the prediction that shifts in host community

337 attributes arising from changes in natural forest cover play an important role in amphibian host-

338 pathogen interactions. Our results indicate that higher-density temperate amphibian assemblages

339 from forested closed-canopy sites are associated with elevated $B d$ loads under constant

340 microclimate, supporting previous findings of elevated disease risk in natural habitats (Becker et al.

341 2012). In contrast, amphibian assemblages from ponds in closed-canopy forests of Brazil carry

342 proportionally lower $B d$ infection loads when microclimate is held constant, due in part to changes

343 in host species composition. Our combined results highlight that disturbances to natural vegetation

344 could either increase or decrease the risk of chytridiomycosis through shifts in host community 
attributes, but that the effects vary depending on the host species pool and how these communities

346 respond to deforestation.

Density-dependent transmission in temperate amphibians

349 If host communities do not vary significantly in species composition, diversity, or genetic factors to

350 resist infection, then higher infection intensities are more likely to occur in denser host populations

351 that promote continuous reinfection of hosts (Briggs et al. 2010). Indeed, laboratory studies show

352 that $B d$ transmission rates in temperate amphibians increase with the density of infected hosts

353 (Rachowicz \& Briggs 2007, Searle et al. 2011, Venesky et al. 2014a). Furthermore, our previous

354 work has showed that denser amphibian populations are more likely to carry higher $B d$ infection

355 loads in the wild, although microclimate effects are often stronger than density-dependent

356 mechanisms shaping $B d$ infections (Becker et al 2012). Specifically, host population density

357 positively predicted $B d$ infection intensity in wild-caught $L$. clamitans when analyzed

358 independently in a simple linear regression, but its effect became non-significant when considered

359 together with other environmental factors such as water temperature and degree of shade at natural

360 sites (Becker et al. 2012). The fact that $B d$ host-pathogen dynamics in climate-controlled

361 mesocosms are strongly density-dependent corroborates earlier population level studies. This result

362 shows that density-dependent transmission can occur at the community level and can be mitigated

363 by microclimatic effects in the wild.

365 Complex responses of diverse tropical amphibians to $\mathrm{Bd}$

366 Deforestation in southeastern Brazil significantly modifies host community attributes (Becker et al. 367 2007) and disease risk (Becker \& Zamudio 2011), and our results indicate that tropical amphibian 368 species commonly found in disturbed habitats carry higher $B d$ infection loads in the laboratory. 
369 Host composition alone could explain the observed pattern, but deforestation can have other

370 detrimental downstream effects on many host parameters that were not quantified in this study such

371 as host immune responses (Carey et al. 1999, Carey 2005) and genetic diversity (Savage \&

372 Zamudio 2011). Additionally, our results could be partially explained by the mesocosm

373 environment. For example, we unexpectedly found a negative relationship between AI and $B d$

374 infection intensities across our experimental communities. This result is primarily due to infections

375 in hylids, which have a low aquatic index (lower exposure to $B d$ in aquatic reservoirs), yet showed

376 disproportionately high pathogen infection loads in mesocosms. Wild hylids may avoid exposure

377 due to arboreal lifestyles, and perhaps were not able to do so as effectively in mesocosms, thus

378 increasing their pathogen burden. Alternatively, owing to their lower natural exposure to $B d$, hylids

379 may not have evolved strong immune responses and are therefore more susceptible to $B d$ in

380 artificial environments.

381 We detected a strong effect of previous exposure to $B d$, in that assemblages carrying high

382 infection loads in the wild showed significantly lower infections in the experimental trials. We now

383 know that a number of species can evolve resistance or tolerance to $B d$ after laboratory infection

384 challenges (Ellison et al. 2014, McMahon et al. 2014, Venesky et al. 2014b). Whether acquired

385 immunity evolved differently in the tropics and temperate zones is unknown. However, exposure

386 varies significantly in the two regions. In the tropics, $B d$ is present in the environment year round

387 (Longo et al. 2010). In contrast, at temperate latitudes $B d$ cycles seasonally (Lenker et al. 2014,

388 Savage et al. 2015), and during much of the year climatic conditions are outside the optimum

389 climatic envelope of $B d$ (Lenker et al. 2014). This shorter exposure to the pathogen could partially

390 explain the overall lower effect of acquired resistance in our temperate host assemblages.

391 Finally, our data show that host density and diversity - two factors known to affect $B d$

392 infection dynamics - may play different roles in the two regions we examined. All else being equal, 
density should enhance transmission probabilities, and thus will be positively correlated with disease risk (Briggs et al. 2010). In contrast, high host diversity often reduces pathogen burden, a mechanism known as the dilution effect (Keesing et al. 2006). Recent studies reported a dilution effect in host- $B d$ systems, such that an increased number of amphibian species reduced infection loads in tadpoles (Searle et al. 2011, Venesky et al. 2014a, Han et al. 2015) and post-metamorphic amphibians (Becker et al. 2014). Therefore, we hypothesized that our mesocosm assemblages with high host diversity would show lower $B d$ infection loads. However, total host density and species

400 richness were positively correlated in our tropical host assemblages. Assemblages with high 401 amphibian density, presumably carrying higher $B d$ infection loads (Searle et al. 2011, Venesky et al. 2014a), also showed elevated host diversity, likely decreasing the odds of infection. These two antagonistic mechanisms likely interact, and therefore it is possible that the unexpected negative density-dependent relationship observed in our tropical amphibian assemblages could be actually a signal of host diversity (dilution effect).

\section{Conclusions}

With the high rate of anthropogenic modification affecting temperate and tropical forests (Chapin et al. 2000), understanding how deforestation influences disease risk is critical for predicting $B d$

410 spread and developing management tools for wild populations. The present study is the first to 411 employ challenge infection experiments linking deforestation with disease risk in mimic amphibian 412 assemblages that differ in species composition and relative abundance, and thus more closely 413 represent natural amphibian communities. Our results highlight that deforestation can lead to an

414 increase or decrease in amphibian disease risk depending on how habitat disturbances change host 415 community structure. Therefore, understanding community-level disease dynamics will require first 416 quantifying the consequences of deforestation for host community structure and then the cascading 
417 effects of altered host community attributes on exposure and subsequent pathogen infections.

418 Regional differences in standing host species diversity will result in distinct and unique pathways

419 when natural systems are disturbed. Understanding these pathways will help us identify case-

420 specific drivers of wildlife epidemics.

\section{Acknowledgements}

423 We thank the Zamudio laboratory for feedback on the manuscript; D.T. Correa, A.L. Torres, N.

424 Pupin, R. Martins, M.A. Passos, A.B.C. Lima, J. Ruggeri, T.A. Pires, A. Talaba for field assistance. 425 Research permits were provided by the ICMCB Brazil (Permits 29964-3; 17242-3), Instituto 426 Florestal - SP (Permit 260108 - 010.479/2012), Universidade Estadual Paulista - UNESP 427 Comissão de Ética no Uso de Animal (Permit 7180), U.S. Fish \& Wildlife Services (Permit 428 2013MI1337329). This research was funded by grants from the National Science Foundation 429 (DEB-1209382 to C.G.B.; DEB-0542848 to K.Z.), Atkinson Center for a Sustainable Future (to 430 C.G.B.), CAPES-Fulbright (Grant 2157-08 to C.G.B.), Department of Ecology and Evolutionary 431 Biology at Cornell University (to C.G.B.), Fundação de Amparo à Pesquisa do Estado de São Paulo 432 (FAPESP 2011/51694-7 to L.F.T., 2008/50928-1 to C.F.B.H.), and Conselho Nacional de 433 Desenvolvimento Científico e Tecnológico - CNPq (to C.F.B.H.).

\section{Appendix A. Supplementary data}

436 Supplementary data associated with this article can be found, in the online version, at XXXXX.

\section{References}


Andersen, L.W., Fog, K. \& Damgaar, C. (2004). Habitat fragmentation causes bottlenecks and inbreeding in the European tree frog (Hyla arborea). Proceedings of the Royal Society of London B, 271, 1293-1302.

Arens, P., et al. (2007). Genetic population differentiation and connectivity among fragmented Moor frog (Rana arvalis) populations in The Netherlands. Landscape Ecology, 22, 14891500.

Becker, C.G., Fonseca, C.R., Haddad, C.F.B., Batista R.F. \& Prado, P.I. (2007). Habitat split and the global decline of amphibians. Science, 318, 1775-1777.

Becker, C.G., Fonseca, C.R., Haddad, C.F.B. \& Prado, P.I. (2010). Habitat split as a cause of local population declines of amphibians with aquatic larvae. Conservation Biology, 24, 287-294.

Becker, C.G. \& Zamudio. K.R. (2011). Tropical amphibian populations experience higher disease risk in natural habitats. Proceedings of the National Academy of Sciences USA, 108, 98939898.

Becker, C.G., Rodriguez, D., Longo-Berrios, A.V., Talaba, A., \& Zamudio, K.R. (2012). Disease risk in temperate amphibian populations is higher at closed-canopy sites. PLoS One, 7:e48205.

Becker, C.G., Rodriguez, D., Toledo, L.F., Longo, A.V., Lambertini, C., Correa, D.T., Leite, D.S., Haddad, C.F.B., \& Zamudio, K.R. (2014). Partitioning the net effect of host diversity on an emerging amphibian pathogen. Proceedings of the Royal Society of London B, 281, 20141796.

Boyle, D.G., Boyle, D.B., Olsen, V., Morgan, J.A.T., \& Hyatt A.D. (2004). Rapid quantitative detection of chytridiomycosis (Batrachochytrium dendrobatidis) in amphibian samples using real-time Taqman PCR assay. Diseases of Aquatic Organisms, 60, 141-148. 
Briggs, C.J., Knapp, R.A., \& Vredenburg V.T. (2010). Enzootic and epizootic dynamics of the chytrid fungal pathogen of amphibians. Proceedings of the National Academy of Sciences USA, 107, 9695-9700.

Carey, C., Cohen, N., \& Rollins-Smith, L. (1999). Amphibian declines: an immunological perspective. Developmental \& Comparative Immunology 23, 459-472.

Carey, C. (2005). How physiological methods and concepts can be useful in conservation biology. Integrative \& Comparative Biology, 45, 4-11.

Chapin, F.S., et al. (2000). Consequences of changing biodiversity. Nature, 405, 234-242.

Costa, M.H., \& Foley, J.A. (2000). Combined effects of deforestation and doubled atmospheric $\mathrm{CO}^{2}$ concentrations on the climate of Amazonia. Journal of Climate, 13, 18-34.

Cushman, S.A. (2006). Effects of habitat loss and fragmentation on amphibians: A review and prospectus. Biological Conservation, 128, 231-240.

Ellison, A.R., Savage, A.E., DiRenzo, G.V., Langhammer, P., Lips, K.R., \& Zamudio, K.R. (2014). Fighting a losing battle: vigorous immune response countered by pathogen suppression of host defenses in a chytridiomycosis-susceptible frog. G3: Genes, Genomes, Genetics, 4, $1275-1289$.

ESRI (2013). Arcview 10. (Redlands, CA).

Fisher, M.C., Garner, T.W.J., \& Walker, S.F. (2009). Global emergence of Batrachochytrium dendrobatidis and amphibian chytridiomycosis in space, time, and host. Annual Review of Microbiology, 63, 291-310.

Gahl, M.K., Longcore, J.E., \& Houlahan, J.E. (2012). Varying Responses of Northeastern North American Amphibians to the Chytrid Pathogen Batrachochytrium dendrobatidis. Conservation Biology, 26, 135-141. 
Gervasi, S., Gondhalekar, C., Olson, D.H., \& Blaustein, A.R. (2013) Host Identity Matters in the Amphibian-Batrachochytrium dendrobatidis System: Fine-Scale Patterns of Variation in Responses to a Multi-Host Pathogen. PLoS One, 8:e54490.

Han, B.A., et al. (2015). Host species composition influences infection severity among amphibians in the absence of spillover transmission. Ecology and Evolution, 5, 1432-1439.

IUCN, Conservation International, NatureServe. (2014). Global amphibian assessment. Available: www.globalamphibians.org. Accessed 10 Mar 2014.

Kapos, V. (1989). Effects of Isolation on the Water Status of Forest Patches in the Brazilian Amazon. Journal of Tropical Ecology 5, 173-185.

Keesing, F., Holt, R.D., \& Ostfeld, R.S. (2006). Effects of species diversity on disease risk. Ecology Letters, 9, 485-498.

Kiesecker, J.M. (2002). Synergism between trematode infection and pesticide exposure: A link to amphibian limb deformities in nature? Proceedings of the National Academy of Sciences USA, 15, 9900-9904.

Kriger, K.M., Pereoglou, F., \& Hero, J.M. (2007). Latitudinal variation in the prevalence and intensity of chytrid (Batrachochytrium dendrobatidis) infection in eastern Australia. Conservation Biology, 21, 1280-1290.

Lenker, M., Savage, A.E., Becker, C.G., Rodriguez, D., \& Zamudio, K.R. (2014). Batrachochytrium dendrobatidis infection dynamics vary seasonally in Upstate New York. Diseases of Aquatic Organisms, 11, 51-60.

Lips, K.R., Reeve, J.D., \& Witters, L.R. (2003). Ecological Traits Predict Amphibian Population Declines in Central America. Conservation Biology, 17, 1078-1088.

LoGiudice, K., Ostfeld, R.S., Schmidt, K., \& Keesing, F. (2003). The ecology of infectious disease: effects of host diversity and community composition on Lyme disease risk. Proceedings of 
the National Academy of Sciences USA, 100, 567-71.

510 Longcore, J.E., Pessier, A.P., \& Nichols, D.K. (1999). Batrachochytrium dendrobatidis gen et sp

511 nov, a chytrid pathogenic to amphibians. Mycologia, 91, 219-227.

512 Longo, A.V., Burrowes, P.A., \& Joglar, R.L. (2010). Seasonal patterns of Batrachochytrium

513 dendrobatidis infection in direct-developing frogs. Diseases of Aquatic Organisms, 92, 253-

514260.

515 McMahon, T.A., et al. (2014). Amphibians acquire resistance to live and dead fungus overcoming

516 fungal immunosuppression. Nature, 511, 224-227.

517 Martel, A. et al. (2014). Recent introduction of a chytrid fungus endangers Western Palearctic $518 \quad$ salamanders. Science, 346, 630-631.

519 Ostfeld, R.S., \& Keesing, F. (2012). Effects of Host Diversity on Infectious Disease. Annual Review of Ecology, Evolution and Systematics, 43, 157-182.

521 Oksanen J et al. 2014 vegan Community Ecology Package. R package v. 2.2-1. http://cran.rproject.org/web/packages/vegan/vegan.pdf.

Pessier, A.P., \& Mendelson, J.R. (2010). A manual for control of infectious diseases in amphibian survival assurance colonies and reintroduction programs (IUCN/SSC Conservation breeding specialist group, Apple Valley, MN).

526 R Core Team. (2014). R: a language and environment for statistical computing. Vienna, Austria: R Foundation for Statistical Computing.

Rachowicz, L.J., \& Briggs, C.J. (2007). Quantifying the disease transmission function: effects of density on Batrachochytrium dendrobatidis transmission in the mountain yellow-legged frog Rana muscosa. Journal of Animal Ecology, 76, 711-721. 
531 Raffel, T.R., Rohr, J.R., Kiesecker, J.M., \& Hudson, P.J. (2006). Negative effects of changing temperature on amphibian immunity under field conditions. Functional Ecology, 20, 819828.

Raffel, T.R., Michel, P.R., Sites, E.W., \& Rohr, J.R. (2010). What drives chytrid infections in newt populations? Associations with substrate, temperature, and shade. EcoHealth, 7, 526-536.

Raffel, T.R., et al. (2013). Disease and thermal acclimation in a more variable and unpredictable climate. Nature Climate Change, 3, 146-151.

Raffel, T.R., et al. (2015). Temperature variability and moisture synergistically interact to exacerbate an epizootic disease. Proceedings of the Royal Society of London B, 282, 20142039.

Rittenhouse, T.A.G., \& Semlitsch, R.D. (2006). Grasslands as movement barriers for a forestassociated salamander: Migration behavior of adult and juvenile salamanders at a distinct

Savage, A.E., Becker, C.G. \& Zamudio, K.R (2015). Linking genetic and environmental factors in habitat edge. Biological Conservation, 131, 14-22.

SAS. (2010). JMP, Version 10. SAS Institute Inc. (Cary, NC).

Savage, A.E., \& Zamudio, K.R. (2011). MHC genotypes associate with resistance to a frog-killing fungus. Proceedings of the National Academy of Sciences USA, 108, 16705-16710.

552 Searle, C.L., Biga, L.M., Spatafora, J.W. \& Blaustein, A.R. (2011). A dilution effect in the 553 emerging amphibian pathogen Batrachochytrium dendrobatidis. Proceedings of the $554 \quad$ National Academy of Sciences USA, 108, 16322-16326. 
555 Skerratt, L.F., et al. (2007). Spread of chytridiomycosis has caused the rapid global decline and extinction of frogs. EcoHealth, 4, 125-134.

557 USGS. (2010). Orthoimagery 2008-2009 at 30 and $15 \mathrm{~cm}$ resolution. Available:

558 http://earthexplorer.usgs.gov. Accessed 2011 Nov 10.

559 Venesky, M.D., et al. (2014a). Linking manipulative experiments to field data to test the dilution $560 \quad$ effect. Journal of Animal Ecology, 83, 557-565.

561 Venesky, M.D., et al. (2014b). Confronting inconsistencies in the amphibian-chytridiomycosis

562 system: implications for disease management. Biological Reviews, 89, 477-483.

563 Woodhams, D.C., Alford, R.A., \& Marantelli, G. (2003). Emerging disease of amphibians cured by 564 elevated body temperature. Diseases of Aquatic Organisms, 55, 65-67. 
566 Table 1. Generalized Linear Model (GLM) simultaneously testing the effects of previous host

567 infection in the wild, host capture rate, average host aquatic index, and NMDS axes depicting host

568 community composition on $B d$ infection intensity across tropical amphibian communities in Brazil,

569 under controlled microclimates in the laboratory. Variance inflation factor (VIF) denotes colinearity

570 in the model when higher than 10.

571

\begin{tabular}{lcccc}
\hline Variable & Std Beta & $\boldsymbol{F}$ & VIF & $\boldsymbol{P}$ \\
\hline$B d$ infection loads in the wild (logGE) & -0.917 & 26.679 & 1.429 & $0.002^{*}$ \\
Host capture rate & -1.175 & 14.887 & 4.202 & $0.008^{*}$ \\
Average host aquatic index (AI) & -1.649 & 13.029 & 9.461 & $0.011^{*}$ \\
NMDS axis 2 & 0.778 & 10.949 & 2.505 & $0.016^{*}$ \\
NMDS axis 1 & 0.437 & 2.112 & 4.094 & 0.196 \\
& & & &
\end{tabular}

Full model statistics: $\mathrm{F}_{[5,6]}=7.862, \mathrm{r}^{2}=0.867, \mathrm{P}=0.013$. 
$574 \quad$ Figure Legends

575

576 Fig. 1. Linear relationships between undisturbed forest cover surrounding temperate ponds in the

577 U.S. and host capture rate (A), and between host density and average $B d$ infection intensities across

578 mesocosm amphibian assemblages (B). Dashed line depicts a marginally significant relationship.

579

580 Fig. 2. Effect of previous $B d$ exposure on infection intensities in tropical amphibians. Linear

581 regression shows a negative relationship between $B d$ infection intensities observed in the wild and

582 in the posterior laboratory controlled experiment across 12 amphibian assemblages in Brazil. 
Figure 1.
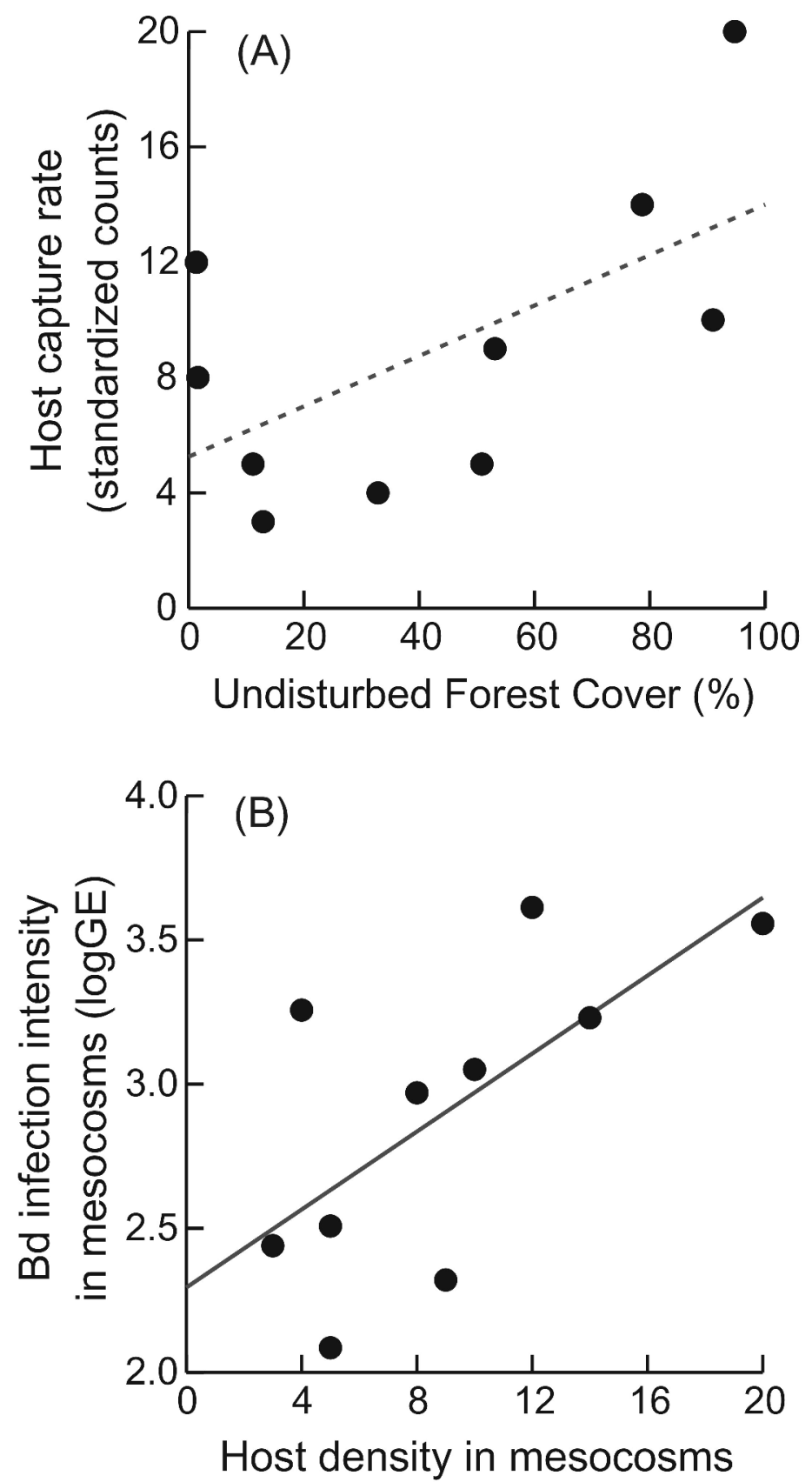
Figure 2.

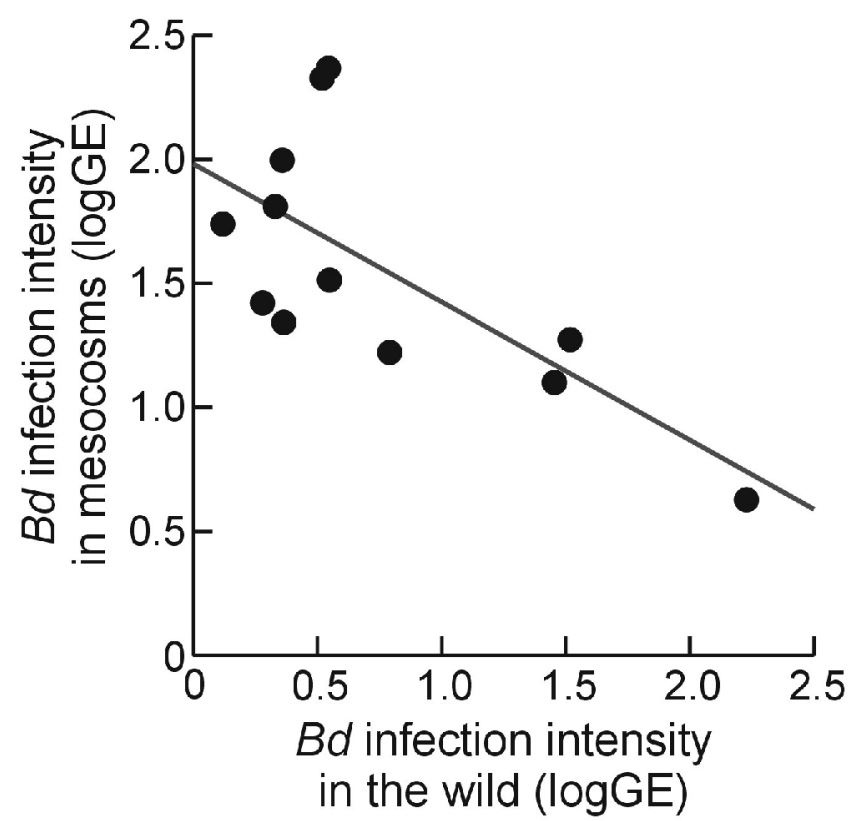

